\title{
A Mathematical Model for Political Bipolarization
}

G. DE MEUR, M. GASSNER, X. HUBAUT

Université Libre de Bruxelles, Belgium

\begin{abstract}
The problem of fair representation is studied in the case of cleavage according to one or two criteria. In the latter case we show that with minimal requirements of equity, a solution exists only if the two criteria are binary. This might explain an observed tendency to political bipolarization.
\end{abstract}

\section{INTRODUCTION}

Problems linked with collective choice, fair representation and comparison of electoral systems have been the object of research in various directions. Most of these studies can be termed unidimensional, since they use only a single criterion for division of the population - position on a right - left political axis, ordered ranking. allocation according to party, region, state - and have yielded important results. We can recall that of Hotelling (1929), for example, which revealed political stability for a bipartite regime, and that of Arrow (1963) showing the possibility of democratic ranking between two candidates. These two results have in common the fact of a privileged situation presenting only two possible states.

The fair representation of a stratified population raises certain difficulties, even when a single criterion has been taken into account. To meet the requirements of equity, the elected delegation should be constructed in a way strictly proportional to the divisions of the mother population; the indivisibility of the men who constitute this representation imposes in addition a solution in whole numbers. These two constraints, generally incompatible, are at the root of numerous problems discussed under the heading of fairness.

A recent book by Balinski and Young (1982) gives a detailed analysis of the subject. Concerning mainly the US House of Representatives apportionment problem, it reviews historical points and provides new results. Perhaps most importantly, they establish that hypotheses of fairness lead to a unique class of apportionment rules, the divisor method. 
Other circumstances necessitate multidimensional treatment, where a population partitioned according to several criteria (parties, regions, languages, etc.) should be able to be fairly represented. It should be noted that this situation goes beyond the political framework, and arises in practice on many occasions, when pre-established balance must be respected between various tendencies: plurality of opinion in the mass media, choice of statistical sample, respect of legal quotas in the personnel of business, etc. In certain countries, in particular in Belgium ('Code Electoral', 1928, 1929 ) and the Netherlands ('Wet Gemeenschappelijke Regelingen', 1950) rules of allocation take into account two criteria simultaneously: in the Dutch system, Anthonisse $(1981,1984)$ picked up some peculiarities in his study of the system of regional delegation. In Belgium, it is common to find consequences of the law of 'apparentement' which go against a more usual sense of fairness.

We have studied the possibility of the constitution of a fair representation in the case where two criteria are in play (for example, party and electoral ward). We show that under hypotheses which are both natural and very mildly constraining, the sole situations which do not give rise to impossibilities are those in which each of the two criteria is binary.

\section{USING A UNIQUE CRTTERION}

The one-dimensional apportionment problem consists of the division of a fixed number of seats according to the size of each of the 'categories' into which the population is divided. The term 'unit' will be used when referring to one of these categories. As noted previously, a perfectly fair division is impossible to achieve, so a compromise must be found, i.e., a distribution of seats with as little variance as possible from the different units' quotas ('share' of delegates merited by the strict proportional rule) and which does not transgress our natural sense of fairness.

Over the years, many different apportionment methods have been proposed and used, each of them having its own qualities and faults. In order to choose among them, one must examine the questions, paradoxes and cases of unfairness raised by each of them. The choice can be difficult, as methods which avoid some paradoxes simply raise others. Some examples of questions raised by the traditional methods are:

1. Can we accept a method which allows a unit to receive more delegates than its quota rounded up?

2. If the total representation size increases, can a unit lose any delegates (if, of course, no outside reason for this should appear)?

3. For a fixed number of delegates to be appointed, if one unit of the population increases while another decreases, can we let the first's apportionment decrease while the second's increases?

4. Should a method 'systematically favour' small units at the expense of large ones, or vice versa?

5. Can one allow the creation of a new unit to change the relative positions of the others?

Answering the first question is easy since some political systems do accept such distortion. One such system is currently used in the Belgin 'legislative' elections. 
Simplifying slightly, we can show how it works (Table I). A population of 100,000 must elect 100 representatives. The votes are cast, and parties $\mathrm{A}, \mathrm{B}$ and $\mathrm{C}$ receive respectively $2,920,95,220$, and 1,860 votes. The first stage of the apportionment is to establish the parties' quotas and to issue 'direct' seats, i.e. whole numbers contained in quotas (Stage A). This way, 98 seats have been assigned. Which party(ies) should get the remaining seats? In a way, they go to the party(ies) which 'offers the most': fictively, one extra delegate is added to each party's total and for each party, the 'value' of a delegate is evaluated (i.e. the number of voters per delegate). The party whose representatives are worth the most voters receives the first extra seat. In our example, it is party B (Stage B). One more seat remains to be assigned. The same procedure is repeated and it is again B which receives the final seat and thus finally finds itself with 97 seats, more than its quota rounded up (Stage C).

TABLE I. Too far from the quota

\begin{tabular}{|c|c|c|c|}
\hline \multirow{2}{*}{ Stage A } & \multicolumn{3}{|c|}{ (100 Representatives - d'Hondt or Jefferson's method) } \\
\hline & Population & Quotas & 'Direct' seats (situation 1) \\
\hline A & 2,920 & 2.92 & 2 \\
\hline B & 95.220 & 95,22 & 95 \\
\hline C & 1,860 & 1.86 & 1 \\
\hline Total & 100,000 & 100 & 98 \\
\hline \multicolumn{4}{|l|}{ Stage B } \\
\hline & 'Direct' seats +1 & Value per delegate & Situation 2 \\
\hline A & 3 & 973.33 & 2 \\
\hline B & 96 & 991.87 & 96 \\
\hline C & 2 & 930 & 1 \\
\hline \multirow{3}{*}{$\begin{array}{l}\text { Total } \\
\text { Stage C }\end{array}$} & & & 99 \\
\hline & & & \\
\hline & Situation $2+1$ & Value per delegate & Final delegation \\
\hline A & 3 & 973.33 & 2 \\
\hline B & 97 & 981.65 & 97 \\
\hline $\mathrm{C}$ & 2 & 930 & 1 \\
\hline Total & & & 100 \\
\hline
\end{tabular}

It must be noted that this procedure is equivalent to computing, for each party, all the quotients which result from dividing these populations by $n+1, n+2 \ldots n+k$, where $\mathrm{n}$ is the number of direct seats and $\mathrm{k}$ the remaining seats, and ranking these quotients in decreasing order: the extra seats go to the party(ies) with the largest quotients. One may wonder why this method is enforced when its faults have been proven, but the reason is simple: while allowing something morally unfair, together with the other 'division methods', it avoids many other paradoxes.

The situation described in our second question can occur in particular when using one of the first apportionment methods, named after its creator, Alexander Hamilton. Hamilton's method gives to each unit the whole number contained in its 
quota, and the remaining seats to those having the largest remainders. Table II shows electoral results for a population which must successively elect ten then eleven representatives, under Hamilton's rule. Even though all the units' sizes remain constant, computations reveal that one of them actually loses a delegate. This paradox is called the 'Alabama paradox', as computations made in the United States in 1880 showed that if the House size was to increase from 299 to 300 Alabama would lose one delegate. So, although this method obviously avoids the unfairness illustrated in Table I, it raises an unacceptable injustice (and, in fact, many more).

TABLE II. Alabama paradox

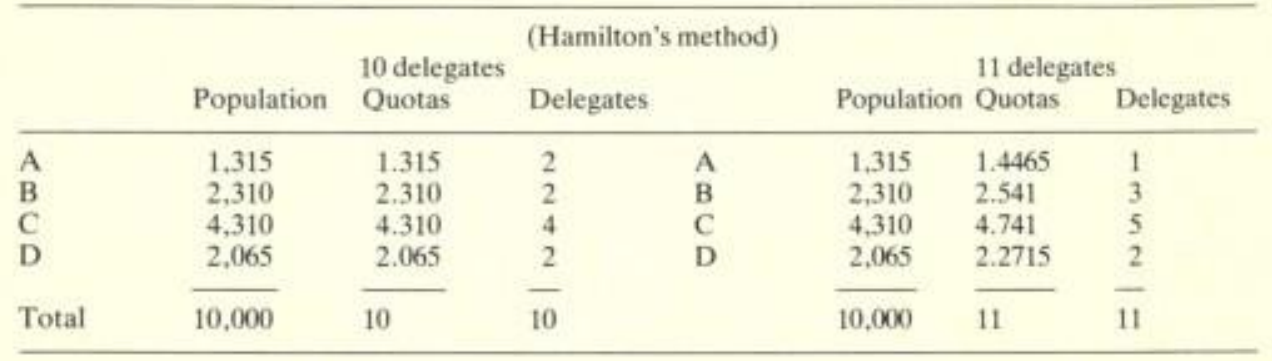

The third question raises yet another problem. Let us again use Hamilton's apportionment method to allot 17 seats in each of the two situations described in Table III. It appears that the representation of unit $\mathrm{C}$ decreases while its size increases, while the opposite is true for unit D.

TABLE III. Population paradox

\begin{tabular}{|c|c|c|c|c|c|c|c|}
\hline \multicolumn{8}{|c|}{ (Hamilton's method) } \\
\hline & \multirow[b]{2}{*}{ Population } & \multicolumn{2}{|c|}{1,000 voters } & \multirow{2}{*}{\multicolumn{2}{|c|}{$\begin{array}{c}1,043 \text { voters } \\
\text { Population Quotas }\end{array}$}} & \multirow{2}{*}{\multicolumn{2}{|c|}{ Delegates }} \\
\hline & & Quotas & Delegates & & & & \\
\hline A & 275 & 4.675 & 5 & A & 304 & 4.955 & 5 \\
\hline B & 177 & 3,009 & 3 & B & 190 & 3.097 & 3 \\
\hline C & 393 & 6.681 & 7 & C & 395 & 6.438 & 6 \\
\hline D & 155 & 2.635 & 2 & D & 154 & 2.510 & 3 \\
\hline Total & 1,000 & 17 & 17 & Total & 1,043 & 17 & 17 \\
\hline
\end{tabular}

The fourth question underlines the fact that an apportionment can be more or less biased. It can be shown that two 'divisor methods', Adams's and Jefferson's, are strongly biased - Adams's in favour of the smaller units, Jefferson's in favour of the larger ones. Let us remind ourselves that Adams's method consists of finding a divisor D such that the smallest integers larger or equal to the units' quotients sum up to the required total of delegates. Table IV compares the results of Table I (Jefferson's method) with those obtained for the same population by Adams's rule. 


\begin{tabular}{|c|c|c|c|c|}
\hline & & (100 representat & ives) & \\
\hline & Population & Adams's quotients & Ada & t Jefferson's \\
\hline & & $($ divisor $=1.010)$ & & \\
\hline A & 2,920 & 2.89 & 3 & 2 \\
\hline B & 95,220 & 94.27 & 95 & 97 \\
\hline C & 1,860 & 1.84 & 2 & 1 \\
\hline Total & 100,000 & & 100 & 100 \\
\hline
\end{tabular}

It is clear that the two smaller units ( $\mathrm{A}$ and $\mathrm{C}$ ) benefit from the use of Adams's method.

Finally, to illustrate the fifth question, Table $V$ shows a new unit (D) joining a population divided into three units: although it brings along its share of seats, one of the other units (A) gives up a seat to yet another (B).

\section{TABLE V. New states paradox}

\begin{tabular}{|c|c|c|c|c|c|c|}
\hline & \multicolumn{6}{|c|}{ (Hamilton's method) } \\
\hline & & 10 seats & & & 12 seats & \\
\hline & Population & Quotas & Delegates & Population & Quotas & Delegates \\
\hline $\mathrm{A}$ & 657 & 6.57 & 7 & 657 & 6.45 & 6 \\
\hline B & 156 & 1.56 & 1 & 156 & 1.53 & 2 \\
\hline C & 187 & 1.87 & 2 & 187 & 1.83 & 2 \\
\hline D & - & - & - & 222 & 2.18 & 2 \\
\hline Total & 1,000 & 10 & 10 & 1,222 & 12 & $\overline{12}$ \\
\hline
\end{tabular}

\section{A TWO-DIMENSIONAL DUTCH ELECTION}

The point of departure of our interest in fair representation, a study by Anthonisse (1981), describes a system currently practised in one of the Netherlands' elections. As said earlier, we find here an example of a multidimensional electoral system, where the population is ranked by two criteria simultaneously, that is, a geographical combined with a partisan division. The vote is a regional one; the voters of a region are characterized by the commune in which they live and by the party of their choice. The first step of the election is for the population of each commune to elect its communal councillors; the second step is for all councillors of a region to designate a number of their members who will form a regional council.

Under Dutch law, 'Each communal council assigns one quarter of its members to the regional council, fractions of five or more being rounded up, fractions under five being rounded down'. The legislators also sxpressed the wish that an effort should be made in order for the political composition of the regional council to match that of the region's communal councils.

The composition of a region's communal council may be summarized in an integer matrix whose elements are numbers of councillors for different parties and 
communes: the element in the ith row and jth column represents the number of communal councillors in commune $\mathrm{C}_{i}$ for party $\mathrm{P}_{\mathrm{j}}$. Similarly for the regional council, $\mathrm{R}$ is derived from $\mathrm{S}$ in the sense that each element of $\mathrm{R}$ must obviously be smaller or equal to a corresponding element in $\mathrm{S}$ (same place in the matrix).

To illustrate the procedure leading to the construction of $\mathrm{R}$, let us examine some examples. Consider a region composed of two communes and three parties whose communal councils are described by the following matrix:

\begin{tabular}{lllll} 
& & & & \multicolumn{2}{c}{ Total } \\
& $P_{1}$ & $P_{2}$ & $P_{3}$ & 8 \\
$C_{1}$ & 3 & 4 & 1 & 8 \\
\hline Total & 3 & 1 & 4 & 16
\end{tabular}

As both communes have eight councillors, the legal rule allows them to name two regional delegates each. Four delegates are thus to be dealt out to three parties in competition, and as the proportion of regional delegates (versus communal councillors) is $25 \%$ (four-sixteenths), the respective global quotas of $P_{1}, p_{2}$ and $P_{3}$ are 1.5, 1.25 and 1.25. By Hamilton's method, which has been used, the parties receive 2, 1 and 1 seats. The marginal sums of the regional matrix are well known at this stage: the remaining problem is to 'fill in' the elements of $\mathrm{R}$ :

\begin{tabular}{lllll} 
& & & & \multicolumn{2}{c}{ (Example 1b) } \\
$\mathrm{C}_{1}$ & $\mathrm{P}_{1}$ & $\mathrm{P}_{2}$ & $\mathrm{P}_{3}$ & 2 \\
$\mathrm{C}_{2}$ & $?$ & $?$ & $?$ & 2 \\
\hline Total & 2 & $?$ & $?$ & 2 \\
\hline
\end{tabular}

A natural idea is to consider each commune as if it were alone, and allot the predetermined number of delegates to a population divided into political categories only. This is done by Hamilton's method. As the proportion of regional delegates for both communes is $25 \%$, the quotas of parties $P_{1}, P_{2}$ and $P_{3}$ are $.75,1$ and .25 in commune $C_{1}$, and $.75, .25$ and 1 in commune $C_{2}$. Rounding them by Hamilton's rule, we obtain

(Example 1c)

\begin{tabular}{lllll} 
& $\mathrm{P}_{1}$ & $\mathrm{P}_{2}$ & $\mathrm{P}_{3}$ & Total \\
$\mathrm{C}_{1}$ & 1 & 1 & 0 & 2 \\
$\mathrm{C}_{2}$ & 1 & 0 & 1 & 2 \\
\hline Total & 2 & 1 & 1 & 4
\end{tabular}

Summing the rows, we obtain the predetermined totals, which is not surprising, as it was imposed by construction. Summing the columns, we also obtain the predetermined marginal values, and this is a coincidence, as nothing in the way we computed the elements of $\mathrm{R}$ could have guaranteed this fact, as is shown by the next situation: 


\begin{tabular}{lllc} 
& & & (Example 2a) \\
$\mathrm{C}_{1}$ & $\mathrm{P}_{1}$ & $\mathrm{P}_{2}$ & Total \\
$\mathrm{C}_{2}$ & 4 & 1 & 5 \\
$\mathrm{C}_{3}$ & 2 & 3 & 5 \\
\hline Total & 2 & 3 & 5 \\
\hline
\end{tabular}

By law, the imposed marginal sums of the regional matrix $\mathrm{R}$ are known:

\begin{tabular}{llll} 
& $\mathrm{P}_{1}$ & $\mathrm{P}_{2}$ & Total \\
$\mathrm{C}_{1}$ & $?$ & $?$ & \\
$\mathrm{C}_{2}$ & $?$ & $?$ & 1 \\
$\mathrm{C}_{3}$ & $?$ & $?$ & 1 \\
\hline Total & 2 & 1 & 3 regional councillors
\end{tabular}

Filling in the elements of $\mathrm{R}$ as in the preceding case, we obtain

\begin{tabular}{lllll} 
& & & (Example 2c) \\
$\mathrm{C}_{1}$ & $\mathrm{P}_{1}$ & $\mathrm{P}_{2}$ & 1 & \\
$\mathrm{C}_{2}$ & 1 & 0 & 1 \\
$\mathrm{C}_{3}$ & 0 & 1 & 1 \\
\hline Total & 0 & 1 & 3 \\
\hline
\end{tabular}

The column sums are not the expected ones; nevertheless, a simple 'transfer' of a seat from party $\mathrm{P}_{2}$ to party $\mathrm{P}_{1}$ within one of the communes (for example in $\mathrm{C}_{2}$ ) can be performed, making the sums correct. So it seems that finding a delegation can be done easily, either immediately, in a natural way, or, if this does not succeed, by transferring one or several delegates from party to party within a same commune. These two cases were forecast by the legislators and both do occur in practice.

Unfortunately, there are some unsolvable cases as illustrated by the following example, and this was the heart of the problem studied by Anthonisse:

\begin{tabular}{llll} 
& $\mathrm{P}_{1}$ & $\mathrm{P}_{2}$ & Total (Example 3a) \\
$\mathrm{C}_{1}$ & 2 & 0 & 2 \\
$\mathrm{C}_{2}$ & 2 & 0 & 2 \\
$\mathrm{C}_{3}$ & 0 & 5 & 5 \\
\hline Total & 4 & 5 & 9 communal councillors
\end{tabular}

Dividing the row sums by 4 and rounding them according to the law, $\mathrm{C}_{1}, \mathrm{C}_{2}$ and $\mathrm{C}_{3}$ must each receive one seat; the size of the regional council is thus three and the proportion of regional councillors is one-third. The predetermined elements of $\mathrm{R}$ are given by:

\begin{tabular}{llll} 
& & & \\
$\mathrm{C}_{1}$ & $\mathrm{P}_{1}$ & $\mathrm{r}^{2}$ & (Example 3b) \\
$\mathrm{C}_{2}$ & $?$ & $?$ & 1 \\
$\mathrm{C}_{3}$ & $?$ & $?$ & 1 \\
\hline Total & $?$ & $?$ & 3 regional councillors
\end{tabular}


It is obvious that the unique delegate in $\mathrm{C}_{1}$ must be chosen in $\mathrm{P}_{1}$, as for the unique delegate in $\mathrm{C}_{2}$, while the unique delegate in $\mathrm{C}_{3}$ comes from $\mathrm{P}_{2}$. This sums up to two delegates for $P_{1}$ and only for $P_{2}$, reversing the predetermined amounts; party $P_{1}$ should give up one seat to party $\mathrm{P}_{2}$, which is clearly impossible.

In fact, this negative result is inherent in the method studied here. Indeed, this Dutch apportionment method (see de Meur et al., 1984) even generalized by replacing divisor 4 by $\mathrm{N}(\geq 4)$, could not avoid impossible situations except in the case where each criterion presents only two alternatives. At this stage, the question that naturally arose was to what extent the impossibilities discovered here were due to the particularity of the system practised in the Netherlands.

\section{TOWARDS FAIRNESS}

The obvious faults of the 'twisted' method of Hamilton and of transfers destroying the original political balance lead us to seek for minimal normative requirements that fair methods of apportionment should respect. So, in order to establish the regional matrix $\mathrm{R}$, we ask ourselves:

(a) Which of its characteristics are predetermined?

(b) Which moral requirements (as weak as possible) should be imposed upon the elements of $R$ ?

To answer the first question, it seems necessary that the sum of the rows (i.e. the numbers of delegates per commune) is predetermined, according to some constraints. first of all, as we are considering a delegation, the numbers of regional delegates per commune must be strictly smaller than the total sizes of the corresponding communal councils. Secondly, the order created by the numbers of communal councillors should not be reversed in the regional council. Finally, it is natural to ask that the difference between the numbers of regional delegates of any two communes must not exceed that of their communal councillors except in the case of a tie (This avoids the immediate impossible situation when the number of delegates to share between two tied communes is odd) in which case this difference should not exceed one. The column sums which are not predetermined, will obey the three same constraints, and they must of course add up to the same total as the predetermined row sums.

Going on to the moral requirements to be imposed upon the elements of $R$, it is tempting to impose for any $\mathrm{i}, \mathrm{j}, \mathrm{k}, \mathrm{I}$ that if party $\mathrm{P}_{1}$ in commune $\mathrm{C}_{\mathrm{k}}$ has more councillors than party $\mathrm{P}_{\mathrm{i}}$ in commune $\mathrm{C}_{\mathrm{i}}$, it should send at least as many delegates as $P_{\text {i }}$ to the regional council. Furthermore, a constraint should be imposed on the difference between the two numbers of councillors, as in the marginal case. The previous conditions, however, seem to be very strong and perhaps artificial in the sense that they are based upon a comparison between absolute numbers, while the problem fundamentally demands a relative balance of those numbers based upon both the communes and the parties. In other words, we should in no way give an equivalent sense to a party of three councillors in a commune of four, and to a party of three in a commune of 100 .

Therefore we chose weaker and somewhat more natural conditions: the order created by the number of communal councillors per party within the same commune 
should not be reversed in the regional council except in the case of a tie. Similarly, the difference between two party sizes in one particular commune (same row of the matrix) should not increase at the regional level, except in the case of a tie. By not demanding that a similar condition should be respected on the columns of $\mathrm{R}$, we are not in contradiction with common political morals or priority to regional divisions: the privilege of negotiated agreements is left to the parties.

To illustrate these conditions let us first examine a situation which obeys all of them; a region is composed of three parties and two communes with the following communal council:

\begin{tabular}{lllll} 
& & & \multicolumn{1}{c}{ (Example 4a) } \\
$C_{1}$ & $\mathrm{P}_{1}$ & $\mathrm{P}_{2}$ & $\mathrm{P}_{3}$ & Total \\
$\mathrm{C}_{2}$ & 52 & 25 & 33 & 110 \\
\hline Total & 26 & 32 & 65 & 123 \\
\hline & 78 & 57 & 98 & 233 \\
& & & & \\
& & & &
\end{tabular}

Suppose its regional delegation is given by:

\begin{tabular}{lllll} 
& & & & Total \\
$\mathrm{C}_{1}$ & $\mathrm{P}_{1}$ & $\mathrm{P}_{2}$ & $\mathrm{P}_{3}$ & 11 \\
$\mathrm{C}_{2}$ & 5 & 3 & 3 & 12 \\
\hline Total & 3 & 3 & 6 & 23 \\
& 8 & 6 & 9 & regional councillors
\end{tabular}

We may check, for example, the marginal conditions required on the row sums:

(i) 11 is strictly smaller than 110 ; 12 is strictly smaller than 123 ;

(ii) 110 is smaller than 123 , and the corresponding 11 is smaller than 12 ;

(iii) the difference between the total councils' sizes of $C_{1}$ and $C_{2}$ is 13 , while the corresponding difference at regional level is only 1 .

All the other requirements are just as easy to verify.

Let us now exhibit a situation which does not obey the whole set of conditions. Suppose that the previous region, in exactly the same situation, had the following regional delegation:

\begin{tabular}{lllll} 
& & & \multicolumn{2}{c}{ (Example 4c) } \\
$\mathrm{C}_{1}$ & $\mathrm{P}_{1}$ & $\mathrm{P}_{2}$ & $\mathrm{P}_{3}$ & 13 \\
$\mathrm{C}_{2}$ & 5 & 3 & 4 & 11 \\
\hline Total & 2 & 3 & 6 & 24 \\
& 8 & 6 & 10 & regional councillors
\end{tabular}

In this case, we immediately notice a violation of our requirements: commune $\mathrm{C}_{1}$ has fewer communal councillors than $\mathrm{C}_{2}$ but receives more regional delegates; the order created among the communes is reversed at the regional level.

The problem now is to study the class of apportionment methods obeying our fairness constraints: if such methods exist (to be proven), how will this class be characterized and how will the method(s) be enforced on concrete situations 
(computation methods). It appears that the existence of such methods is only possible in a very restricted outline and we will describe how they work in that case.

Indeed, the picture shown in Examples $3 \mathrm{a}$ and $3 \mathrm{~b}$, which revealed itself insoluble by Anthonisse's method, appears again to lead to impossibilities whichever apportionment method which satisfies our constraints, as weak as they are, could be used. One can wonder why this occurs. Perhaps the example is too particular as the presence of zeros, especially while dealing with votes, seems very improbable. Furthermore, it is not 'connected' in the sense that the set of communes can be separated into two groups $\left(\mathrm{C}_{1}, \mathrm{C}_{2}\right)$ and $\left(\mathrm{C}_{3}\right)$ in such a way that no party has a seat in both groups at the same time.

These apt criticisms can be constructed by the following examples. First, let us take the case of three communes and two parties:

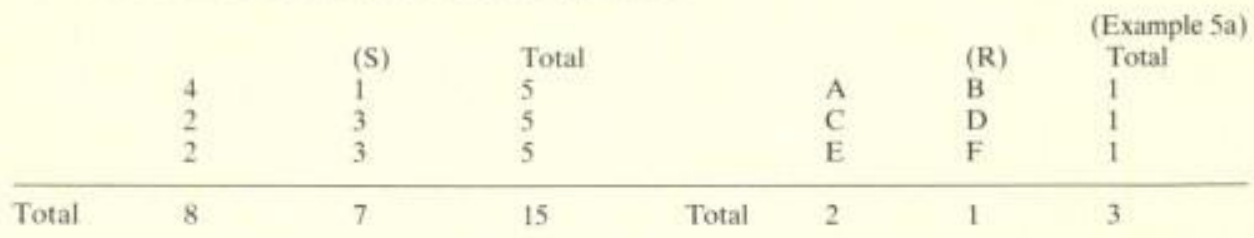

If we insist that each commune receive one regional delegate (this obeys the conditions), then three delegates are to be distributed amongst the two parties. The only way to do this without violating the moral requirements is for party 1 to receive two delegates and party 2 to receive one delegate. In order to determine A, B, C, D, $E$ and $F$, one must remember the constraints upon the elements of $R$. First, B must be smaller or equal to $\mathrm{A}$, but $\mathrm{A}+\mathrm{B}$ must equal 1 ( so $\mathrm{A}=1$ and $\mathrm{B}=0$ ); and second, by the same arguments, $D$ and $F$ must equal 1 , while $C$ and $E$ equal 0 . Unfortunately, summing $\mathrm{A}, \mathrm{C}$ and $\mathrm{E}$ we obtain 1 , while $\mathrm{B}+\mathrm{D}+\mathrm{F}=2$, reversing the predetermined column sums.

Second, take the case of two communes and three parties:

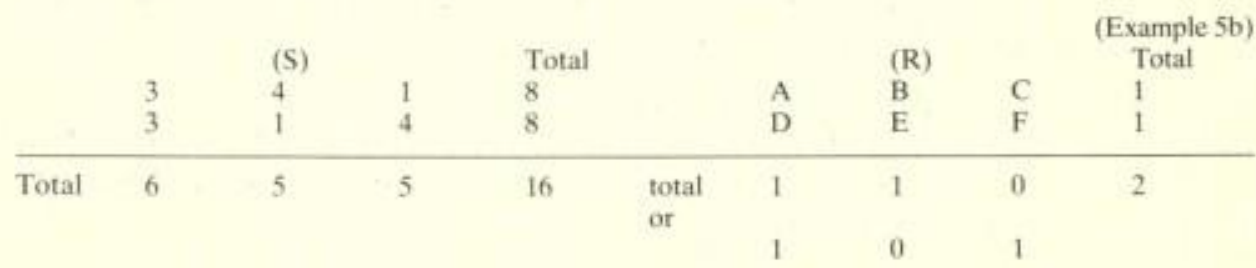

Interesting again that each commune receive one delegate, it is easy to show that this leads to a contradiction. We were thus forced to concede that, even with weak requirements of equity, the impossibility of a choice of a delegation conforming to them can occur when at least one of the two criteria of division consists of more than two possibilities. We then went on to suggest the existence of apportionment methods which respect all the above-mentioned rules in the binary case of two communes and two parties. As in the Dutch election system, this is thus the only feasible case, and we shall now sketch how to handle this case. (The complete proof will be sent by the authors to any person's request.)

The first step is to consider each commune separately, giving to each party half of the regional delegates for the commune (if that number is even) or half plus one to the largest party of the commune (if it is odd), and what is left to the other party 
(Example 6a): (If this is not possible, give as many seats as possible to the smaller party, and the remainder to the larger one (Example 6b).

This certainly does not violate our atomic conditions on matrix $\mathbf{R}$.

The second step is to sum the columns, and either the marginal conditions are met (and the matrix constructed above is R), or they are not; in the latter case, seats should be transferred within the communes, without exceeding the limits set by the atomic conditions, until the marginal conditions are met:

\begin{tabular}{rrrrrrrl}
2 & 7 & 9 & delegation & 1 & 2 & 3 & (Example 6a) \\
4 & 3 & 7 & & 1 & 2 & \\
\hline 6 & 10 & 16 & (figure 11a) & 2 & 3 & 5 & predetermined \\
2 & 7 & 9 & 2 & 4 & 6 & (Example 6b) \\
4 & 3 & 7 & 3 & 2 & 5 & \\
\hline 6 & 10 & 16 & 5 & 6 & 11 & \\
\hline
\end{tabular}

(Example 7)

\begin{tabular}{rrrrrrrrr} 
& (S) & & & & & (R) & \\
6 & 4 & 10 & 1 st step 2 & 2 & 4 & 2nd step 3 & 1 & 4 \\
5 & 6 & 11 & 2 & 3 & 5 & 2 & 3 & 5 \\
\hline 11 & 10 & 21 & 4 & 5 & 9 & 5 & 4 & 9
\end{tabular}

As $11>10$ but $4<5$, we transfer one seat from $P_{2}$ to $P_{3}$ in the first row.

\section{CONCLUSION}

Even with the weakest conditions on equity we are confronted with a result suggestive of Arrow's theorem and we are forced to conclude that a model for political situations involving at least two division criteria should take into account this explanation of a tendency towards bipolarization for each of the chosen criteria.

Yet, in practice, different rules of assignment are used in various countries, and function nevertheless. This is due to the fact that, in general, a set of favourable conditions is gathered together: the delegation is small with regard to the initial membership; the different matrix entries have comparable orders of magnitude (communes of electoral constituencies being of roughly the same size and small parties being either excluded or negligible in all places); the initial data still give sufficient relative differences to ensure the possibility of transfers, given the sizes of membership in play, etc. . Even so, some concrete situations incorporate 'anomalies' which give a sense of a tendency towards impossibility for extreme cases, as we have shown, or which quite simply present a violation of the conditions of fairness used in this work, weak as they are, as, for example, in systems where each constituency chooses a single representative (France, Great Britain).

One should, nevertheless, not draw the conclusion that our quest for equity must stop here. It is necessary to continue a normative search, not only to be able to understand existing phenomena, but most of all to try to improve them. Our natural and simple constraints allow many changes towards more flexibility and future research. One idea would be to rid the model of its most arbitrary constraint, that is 
the predetermined character of the total numbers of regional representatives per commune (indeed, this condition, induced by a desire for concrete feasibility, does not add to our search for equity). These numbers could be determined a posteriori, taking into account the peculiarities of the matrix S, within acceptable limits which could be set beforehand. Another direction for generalization is given by the problems met by Switzerland where two dimensions are not sufficient. Our conjecture here is that an immediate extension of our two-dimension results should be expected, meaning that the only feasible cases will remain the binary ones, leading us to a generalized bipolarization.

\section{REFERENCES}

Anthonisse, J. M. (1981) "Geografische en Politieke Samenstelling van de Gewestraad, Congress Communication in Brussels, 4th Meeting of the Contact Group FNRS "Mathematical Models in Human Sciences'.

Anthonisse, J. M. (1984) 'Evenredige Vertegenwoordiging in het Kader van Gemeenschappelijke Regelingen', Notitie OS-N8401 (1984), Afedling Mathematische Besliskunde en Systeemtheorie, Centre for Mathematics and Computer Science, Amsterdam.

Arrow, K. J. (1963). Social Choice and Individual Values, New York: Wiley.

Balinski. M. L. and Young H. P. (1982). Fair Representation Meeting the Ideal of One Man, One Vote. New Haven and London: Yale University Press.

'Code Electoral', Moniteur Belge du 19/8/1928 \& 28/4/1929, Belgium.

De Meur, G.. Gassner, M. and Hubaut, X. (1984). The Problem of Representation based upon Two Criteria', 365-75, in Degreef E, and Van Buggenhaut, J., eds, Trends in Mathematical Psychology. Advances in Psychology (20), Amsterdam, North-Holland.

Hotelling. H. (1929). Stability in Competition, Economic Journal 39, 41-57.

'Wet Gemeenschappelijke Regelingen' 1/4/1950 Gemeenstewet 'Schuurmans en Jordens', $n^{\circ} 4$, in Staatsblad $\mathrm{n}^{n} \mathrm{~K} 120$, Netherland. 